\title{
Clinicopathological significance of microRNA-31, -143 and -145 expression in colorectal cancer
}

\author{
Chao-Jie Wang ${ }^{\mathrm{a}}$, Zong-Guang Zhou ${ }^{\mathrm{a}}$, Ling Wang ${ }^{\mathrm{a}}$, Lie Yang ${ }^{\mathrm{a}}$, Bin Zhou ${ }^{\mathrm{a}}$, Jun Gu ${ }^{\mathrm{a}}$, \\ Hong-Ying Chen ${ }^{\mathrm{a}}$ and Xiao-Feng Sun ${ }^{\mathrm{a}, \mathrm{b}, *}$ \\ ${ }^{a}$ Institute of Digestive Surgery and Department of Colorectal Surgery, and State Key Laboratory of Biotherapy, \\ West China Hospital, Sichuan University, Chengdu, China \\ ${ }^{\mathrm{b}}$ Department of Oncology, Institute of Clinical and Experimental Medicine, University of Linköping, Linköping, \\ Sweden
}

\begin{abstract}
We are just beginning to understand how microRNAs (miRNAs) are involved in tumor-related processes in humans. Applying real-time RT-PCR, we investigated the miR-31, miR-143 and miR-145 expression in 98 primary CRC specimens, along with the corresponding normal mucosa specimens, and analyze the relationship of their expression with clinicopathological features. Our results showed the miR-31 expression was up-regulated in CRC compared to normal mucosa $(p=0.001)$. Furthermore, miR-31 expression was positively related to advanced TNM stage $(p=0.026)$ and deeper invasion of tumors $(p=$ $0.024)$. MiR-145 was down-regulated in both colon $(p=0.001)$ and rectal $(p=0.012)$ cancer. MiR-143 was only down-regulated in colon cancer $(p=0.023)$ but not in rectal cancer $(p=0.351)$. There was no relationship of miR-143 and miR-145 expression with other clinicopathological features $(p>0.05)$, except that the miR-145 expression was related to cancer site $(p=0.03)$. In conclusion, the miR-31 overexpression may be involved in the development and progression of CRC. The miR-143 and miR-145 may play a certain role in the development of colon and/or rectal cancers but not in progression of the disease.
\end{abstract}

Keywords: microRNA, colorectal cancer, tumor stage, real-time RT-PCR

\section{Introduction}

MicroRNAs (miRNAs) are non-coding, singlestranded RNAs of $\sim 22$ nucleotides function as posttranscriptional gene regulators, and are found in plants, animals and humans [1]. So far, 695 miRNAs in humans have been identified according to the miRBASE (release 12.0, September, 2008, http://microrna.sanger.ac.

*Corresponding author: Xiao-Feng Sun, Prof., MD, PhD, lecture professor of "Cheung Kong Scholars" of Sichuan University. Institute of Digestive Surgery, West China Hospital, Sichuan University, Chengdu, 610041, Sichuan, China. Tel.: +86 28 85164035; Fax: +8628 85164035. Department of Oncology, Institute of Clinical and Experimental Medicine, University of Linköping, S-581 85 Linköping, Sweden. Tel.: +46 13 222066; Fax: +46 13 223090; E-mail: xiasu@ibk.liu.se. uk). More and more studies have shown that miRNAs take part in the regulation of cellular development, differentiation, proliferation, and apoptosis [2-5]. In 2002, Calin et al. found that the miR-15a and miR16-1 were either absent or down-regulated in $68 \%$ of patients with B-cell chronic lymphocytic leukemia, and they provided the initial evidence for the involvement of miRNAs in human malignancy [6]. From then on, increasing evidence indicates that aberrant expression of miRNAs present in different types of cancers, including colorectal, lung, breast, pancreatic, cervical, ovarian and prostate cancers [7-13]. Furthermore, it has been shown that miRNAs can function as tumor suppressors or oncogenes, and repress the expression of important cancer-related genes, and might prove useful biomarkers in the diagnosis and treatment of cancers $[14,15]$. 
MicroRNA-31 (miR-31), located at chromosome 9p21.3, was first identified in HeLa cell [16]. Bandrés et al. found the miR-31 was up-regulated in 12 pairs of colorectal cancers (CRCs) and non-tumoral mucosa samples from the patients, and tumors with TNM stage IV $(n=5)$ had a significantly up-regulated miR-31 expression than those with stage II $(n=5)$ [17]. In contrast to this, another study found no association between miR-31 expression levels and the TNM stage [18].

MicroRNA-143 (miR-143) and microRNA-145 (miR-145), located at chromosome 5q32, were first identified in mouse [19]. Shortly after, both of them were verified in humans, and demonstrated significantly reduced levels at the adenomatous and cancer stages of colorectal neoplasm [7]. From then on, miR-143 and/or miR-145 aberrant expression have/has been documented in diverse human malignancies, including not only clinical specimens such as breast [9], cervical [11], ovarian [12] and prostate cancers [13], B-cell malignancies [20], but also human cell lines such as colon, cervical, hepatic, prostate cancers, and neuroblastoma as well as various leukemia [21]. The miRNAs which have roles in cancer development are designated as oncogenic miRNAs (oncomiRs) [22], therefore miR143 and $\mathrm{miR}-145$ are possible common oncomiRs since their aberrant expression has been found in various human malignancies [21]. Furthermore, miR-145 was progressively down-regulated from normal breast to cancer with high proliferation index, which implicated the miR-145 had a relationship with clinical parameters in breast cancer [9].

Since the mature miRNAs are only $\sim 22$ nucleotides in length, they can not be detected by the conventional reverse transcription (RT)-PCR. A mature miRNA quantification method has been developed using stemloop RT followed by TaqMan PCR analysis. First, the stem-loop RT primer is hybridized to a miRNA molecule and then reverse transcribed with the reverse transcriptase. Next, the RT products are quantified using conventional TaqMan PCR. This method is specifically quantifies mature miRNA expression level with superior performance over existing conventional detection methods [23].

In this study, we used stem-loop RT-PCR to quantify the miR-31, -143 and -145 expression in a series of 98 primary CRCs, along with the corresponding normal mucosa. Our aim was to investigate the miR-31, -143 and -145 expression in CRC and their relationships to clinicopathological variables in the patients.

\section{Materials and methods}

\subsection{Patients and tissue samples}

The study included 98 patients with primary CRC diagnosed and treated at the West China Hospital, Chengdu, China, between 2005 and 2006. For each case, samples from primary tumor and the corresponding normal colorectal mucosa were collected for comparison. All samples were flash-frozen in liquid nitrogen, and stored at $-80^{\circ} \mathrm{C}$. The samples were examined for the presence of tumor cells, usually tumor cells were at least around $80 \%$, at the Department of Pathology in the West China Hospital. The eligible tumors must be primary CRC with no preoperative radiotherapy or chemotherapy. This study was carried out with Medical Ethical Committee approval and informed consent in writing was obtained from each patient. The patient's gender, age, tumor site, TNM stage, local invasion, vessel invasion, differentiation and sera carcinoembryonic antigen (CEA) were obtained from surgical and pathological records from the Hospital. The mean age was 54.3 years (ranging from 24 to 83). Local invasion was classified as tumor invading submucosa (T1), muscularis propria (T2), through muscularis propria into subserosa or into non-peritonealized pericolic or perirectal tissues (T3), and into other organs or structures and/or perforated visceral peritoneum (T4) [24]. Differentiation was graded as better (including well and moderately differentiated tumors) and worse (including poorly differentiated, mucinous and signet-ring cell carcinoma). CEA values were obtained from 27 patients.

\subsection{RNA extraction and reverse transcriptase reactions}

Total RNA of CRC and the corresponding normal mucosa was isolated using TRI reagent (Molecular Research Center, Inc., OH, USA) according to the manufacturer's instructions and treated with DNase I.

We designed miR-31, -143 and -145 stem-loop RT primers (supplementary Table 1) according to the method developed by Chen et al. [23], and purchased the primers from Invitrogen (Invitrogen Biotechnology Co., Ltd, Shanghai, China). To generate cDNA of miRNA, 25 ng of RNA was first denatured at $70^{\circ} \mathrm{C}$ with $50 \mathrm{nM}$ stem-loop RT primer for $5 \mathrm{~min}$ before quenching on ice, and then $1 \mathrm{mM}$ final of each of the four deoxynucleotide triphosphates, $1 \mathrm{U} / \mu \mathrm{l}$ ribonuclease inhibitor, $10 \mathrm{U} / \mu 1 \mathrm{M}-\mathrm{MLV}$ reverse transcriptase and $1 \times \mathrm{M}-\mathrm{MLV}$ RT buffer (TaKaRa Biotechnology Co., Ltd, Dalian, 
Supplementary Table 1

The sequence of miR-31, miR-143 and miR-145 stem-loop RT primers

\begin{tabular}{ll}
\hline RT primer & Sequence \\
\hline miR-31 & 5'-GTCGTATCCAGTGCTGGGTCCGAGTGATTCGCACTGGATACGACCAGCTA-3' \\
miR-143 & 5'-GTCGTATCCAGTGCTGGGTCCGAGTGATTCGCACTGGATACGACTGAGCTACA-3' \\
miR-145 & 5'-GTCGTATCCAGTGCTGGGTCCGAGTGATTCGCACTGGATACGACAAGGGATTC-3' \\
\hline
\end{tabular}

Supplementary Table 2

Specific primers and probes for miRNAs and 5S rRNA

\begin{tabular}{ll}
\hline & Sequence \\
\hline miR-31 & \\
Forward primer & 5'-ACGCGGCAAGATGCTGGCA-3' \\
Reverse primer & 5'-CAGTGCTGGGTCCGAGTGA-3' \\
Probe & 5'-FAM-TCGTATCCAGTGCGAATGACTC-TAMRA-3' \\
miR-143 & \\
Forward primer & 5'-CCTGGCCTGAGATGAAGCAC-3' \\
Reverse primer & 5'-CAGTGCTGGGTCCGAGTGA-3' \\
Probe & 5'-FAM-TCGTATCCAGTGCGAATGACTC-TAMRA-3' \\
miR-145 & \\
Forward primer & 5'-GGCGTCCAGTTTTCCCAG-3' \\
Reverse primer & 5'-CAGTGCTGGGTCCGAGTGA-3' \\
Probe & 5'-FAM-TCGTATCCAGTGCGAATGACTC-TAMRA-3' \\
5S rRNA & \\
Forward primer & 5'-TACGGCCATACCACCCTGA-3' \\
Reverse primer & 5'-GGCGGTCTCCCATCCAA-3' \\
Probe & 5'-FAM-CCCGACCCTGCTTAGCTTCCGA-TAMRA-3' \\
\hline
\end{tabular}

China) were added together to make up a final volume of $10 \mu \mathrm{l}$ reaction mix. The reaction mix was incubated in PTC- $100^{\mathrm{TM}}$ Programmable Thermal Controller (MJ Research, Inc., MA, USA) for $30 \mathrm{~min}$ at $16^{\circ} \mathrm{C}, 30 \mathrm{~min}$ at $42^{\circ} \mathrm{C}$. The reverse transcriptase was inactivated at $85^{\circ} \mathrm{C}$ for $5 \mathrm{~min}$ and then held at $4{ }^{\circ} \mathrm{C}$.

To generate cDNA of $5 \mathrm{~S}$ rRNA, $5 \mu \mathrm{g}$ of RNA was first denatured at $70^{\circ} \mathrm{C}$ with $2.5 \mathrm{mM}$ random hexamers (TaKaRa Biotechnology Co., Ltd) for $5 \mathrm{~min}$ before quenching on ice, and then $1 \mathrm{mM}$ final of each of the four deoxynucleotide triphosphates, $1 \mathrm{U} / \mu$ l ribonuclease inhibitor, $10 \mathrm{U} / \mu \mathrm{l} \mathrm{M}-\mathrm{MLV}$ reverse transcriptase and $1 \times$ M-MLV RT buffer were added together to make up a final volume of $20 \mu \mathrm{l}$ reaction mix. The reaction mix was incubated in PTC- $100^{\mathrm{TM}}$ Programmable Thermal Controller for $10 \mathrm{~min}$ at $20^{\circ} \mathrm{C}$ and $1 \mathrm{~h}$ at $42^{\circ} \mathrm{C}$. The reverse transcriptase was inactivated at $70^{\circ} \mathrm{C}$ for $10 \mathrm{~min}$ and then held at $4^{\circ} \mathrm{C}$.

\subsection{Real-time PCR analysis for miRNAs expression}

The miR-31, -143, -145 and endogenous control 5S rRNA primers and probes (supplementary Table 2) were purchased from the Invitrogen. Theoretical basis real-time PCR was performed using relative quantification protocol on an $\mathrm{iCycer}_{\mathrm{iQ}} \mathrm{TM}^{\mathrm{TM}}$ System (Bio-Rad, CA, USA). The $30 \mu \mathrm{l}$ PCR included $1 \mu \mathrm{l}$ RT product, $0.33 \mu \mathrm{M}$ TaqMan probe, $0.33 \mu \mathrm{M}$ forward primer,
$0.33 \mu \mathrm{M}$ reverse primer, $1 \times$ buffer $\left(\mathrm{Mg}^{++}\right.$free $), 0.3 \mathrm{mM}$ each of the four deoxynucleotide triphosphates, $2.5 \mathrm{mM}$ $\mathrm{MgCL}_{2}$, and $1.5 \mathrm{u}$ rTaq DNA Polymerase (TaKaRa Biotechnology Co., Ltd). The reactions were incubated in a 96 well plate at $94^{\circ} \mathrm{C}$ for $3 \mathrm{~min}$, followed by 40 cycles of $94^{\circ} \mathrm{C}$ for $20 \mathrm{~s}, 55^{\circ} \mathrm{C}$ for $25 \mathrm{~s}$, and $60^{\circ} \mathrm{C}$ for $35 \mathrm{~s}$. All reactions, including no-template control, were run in triplicate. The PCR product of miRNA was about $60 \mathrm{bp}$ in length and the reference gene 5S rRNA was about $90 \mathrm{bp}$. The threshold cycle $(\mathrm{Ct})$ is defined as the fractional cycle number at which the fluorescence passes the fixed threshold. Equation (1) was applied to calculate the relative expression ratio of the target gene in a sample versus a control in comparison to a reference gene [25].

$$
\begin{aligned}
\text { Ratio }= & \mathrm{E}_{\text {target }}^{\Delta \text { CTtarget(control-sample) }} / \\
& \mathrm{E}_{\text {reference }}^{\Delta \mathrm{CTref}(\text { control-sample })}
\end{aligned}
$$

$E_{\text {target }}$ and $E_{\text {ref }}$, respectively represents the real-time PCR efficiency of target gene and reference gene transcript. $\Delta \mathrm{CT}_{\text {target(control-sample), }}$ $\Delta \mathrm{CT}_{\text {ref(control-sample) }}$ is the $\mathrm{Ct}$ deviation of control minus sample of the target or reference gene transcript. To determine PCR efficiency, five-fold dilution of CRC genomic cDNA and miRNA cDNA were diluted for five times $(1,1: 5,1: 25,1: 125,1: 625$ and 1:3125). Both $5 \mathrm{~S}$ rRNA and miRNA were amplified by real-time PCR 
Table 1

Output of randomization test in normal mucosa and tumor from colorectal cancer patients

\begin{tabular}{lccccc}
\hline & $\begin{array}{c}\text { Patient } \\
(\text { No })\end{array}$ & $\begin{array}{c}\text { Ct T } \\
\text { Mean } \pm \text { SD }\end{array}$ & $\begin{array}{c}\text { Ct N } \\
\text { Mean } \pm \text { SD }\end{array}$ & $\begin{array}{c}\text { Expression ratio } \\
(\mathrm{R})\end{array}$ & $\mathrm{p}$ \\
\hline miR-31 & 98 & $21.48 \pm 8.61$ & $25.43 \pm 5.09$ & 15.00 & 0.001 \\
miR-143 & 98 & $14.88 \pm 3.16$ & $14.30 \pm 4.54$ & 0.67 & 0.098 \\
miR-145 & 98 & $14.43 \pm 3.53$ & $13.14 \pm 3.86$ & 0.42 & 0.001 \\
5S rRNA & 98 & $14.90 \pm 3.76$ & $14.92 \pm 4.50$ & & \\
\hline
\end{tabular}

T, tumor; N, normal mucosa; SD, standard deviation.

using the identical conditions established for the gene expression analysis. Plots were made of the log of the template concentration versus the $\mathrm{Ct}$, and the PCR efficiency was calculated from the slope of the line using the Equation: $\mathrm{E}=10^{(-1 / \text { slope })}[26]$. The actual concentration of the template is not needed when determining the efficiency as it depends only upon the slope of the line.

\subsection{Statistical analysis}

The relative expression analysis of target gene was performed using REST-XL (Relative Expression Software Tool, available at http://www.wzw.tum.de/genequantification). The expression ratio was calculated according to the Eq. (1), and then the data were presented as $\log _{10}$ of relative quantity (RQ). Student's ttest was performed using the SPSS 11.5 statistical software package (SPSS, Inc., Illinois, USA) to test for the significance of the expression ratio of miRNA with the clinicopathological features. Chi-square test was used to test relationships of the combined expression of the miRNAs with clinicopathological features. Tests were two-sided, and $p<0.05$ was considered as statistically significant.

\section{Results}

\subsection{Expression of miRNA in CRC and the corresponding normal mucosa}

In Eq. (1) as described in the materials and methods section, the relative expression ratio $(\mathrm{R})$ was presented as the fold change in gene expression normalized to an endogenous reference gene and relative to the control. Therefore, the value of $R>1.0$ was considered to represent overexpression of miRNA in cancer relative to the normal mucosa, $R<1.0$ represent downexpression. Among $98 \mathrm{CRCs}, 89(91 \%)$ cancers showed miR-31 overexpression, of which $62(63 \%)$ cancers had $>10$ times higher expression and 17 (17\%) cancers had
$>100$ times higher expression of miR-31, relative to the normal mucosa; Fifty-six (57\%) cancers showed miR143 downexpression, of which $15(15 \%)$ cancers had $>10$ times lower expression and $2(2 \%)$ cancers had $>100$ times lower; Sixty-six $(67 \%)$ cancers showed miR-145 downexpression, of which $16(16 \%)$ cancers had $>10$ times lower expression and $4(4 \%)$ cancers had $>100$ times lower.

To further compare the overall level of each miRNA expression in CRC relative to normal mucosa, we put the $\mathrm{Ct}$ values for reference and target genes both in CRC and normal mucosa into the REST-XL software, and chose 2000 as the randomization number. The results of the randomization test showed that the miR-31 was up-regulated in cancer compared to normal mu$\operatorname{cosa}(R=15.00, p=0.001)$, the miR-145 was downregulated ( $R=0.42, p=0.001)$. The expression of miR-143 was also down-regulated $(R=0.67)$ although the difference did not reach statistically significance $(p=0.098$, Table 1$)$.

We further analyzed the expression level of miRNA in tumor compared to normal mucosa according to tumor site. As shown in Table 2, the up-regulated miR31 and down-regulated miR-145 were seen in the both colon and rectum $(p<0.05)$, while the down-regulated miR-143 was only seen in the colon $(p=0.023)$ but not in rectum $(p=0.351)$.

\subsection{Relationship between miRNA and clinicopathologicalfeatures}

The relative quantification values were transformed as $\log _{10}$, so the data were normally distributed and Student's t-test was verified between miRNA expression and clinicopathological features. As shown in Table 3, the miR-31 expression was related to TNM stage ( $p=$ $0.026)$ and local invasion $(p=0.024)$. The miR-31 expression was higher in tumors having more advanced TNM stage and deeper invasion. The miR-145 expression was related to cancer site $(p=0.03)$, and had no relationship with gender, age, TNM stage, local invasion, differentiation, vessel invasion and sera CEA lev- 
Table 2

Output of randomization test in normal mucosa and tumor according to tumor site

\begin{tabular}{lccccc}
\hline & $\begin{array}{c}\text { Patient } \\
(\mathrm{No})\end{array}$ & $\begin{array}{c}\mathrm{Ct} \mathrm{T} \\
\text { Mean } \pm \mathrm{SD}\end{array}$ & $\begin{array}{c}\mathrm{Ct} \mathrm{N} \\
\text { Mean } \pm \mathrm{SD}\end{array}$ & $\begin{array}{c}\text { Expression ratio } \\
(\mathrm{R})\end{array}$ & $\mathrm{p}$ \\
\hline Colon & 17 & & & & \\
miR-31 & & $21.55 \pm 6.44$ & $24.94 \pm 6.25$ & 10.46 & 0.002 \\
miR-143 & & $15.96 \pm 1.76$ & $14.34 \pm 3.44$ & 0.34 & 0.023 \\
miR-145 & & $16.08 \pm 1.74$ & $13.38 \pm 2.69$ & 0.17 & 0.001 \\
5S rRNA & & $14.71 \pm 3.17$ & $14.68 \pm 1.71$ & & \\
Rectum & 81 & & & & \\
miR-31 & & $21.47 \pm 9.15$ & $25.53 \pm 4.86$ & 16.18 & 0.001 \\
miR-143 & & $14.66 \pm 3.18$ & $14.29 \pm 4.82$ & 0.77 & 0.351 \\
miR-145 & & $14.08 \pm 3.22$ & $13.08 \pm 4.13$ & 0.50 & 0.012 \\
5S rRNA & & $14.94 \pm 3.91$ & $14.97 \pm 5.10$ & & \\
\hline
\end{tabular}

T, tumor; N, normal mucosa; SD, standard deviation.

Table 3

Relationship between miR-31, miR-143, miR-145 expression and clinicopathological features in colorectal cancer patients

\begin{tabular}{|c|c|c|c|c|c|c|c|}
\hline \multirow[b]{2}{*}{ Variable } & \multirow[b]{2}{*}{ No } & \multicolumn{2}{|c|}{ miR-31 } & \multicolumn{2}{|l|}{ miR-143 } & \multicolumn{2}{|l|}{ miR-145 } \\
\hline & & Mean \pm SD & $\mathrm{p}$ & Mean \pm SD & $\mathrm{p}$ & Mean \pm SD & $\mathrm{p}$ \\
\hline Gender & & & 0.589 & & 0.485 & & 0.561 \\
\hline Male & 51 & $1.226 \pm 1.095$ & & $-0.117 \pm 0.897$ & & $-0.333 \pm 0.850$ & \\
\hline Female & 47 & $1.122 \pm 0.775$ & & $-0.241 \pm 0.849$ & & $-0.433 \pm 0.833$ & \\
\hline Age (yr) & & & 0.304 & & 0.202 & & 0.355 \\
\hline$\leqslant 55$ & 45 & $1.284 \pm 0.892$ & & $-0.299 \pm 0.830$ & & $-0.467 \pm 0.781$ & \\
\hline$>55$ & 53 & $1.085 \pm 0.998$ & & $-0.072 \pm 0.902$ & & $-0.308 \pm 0.886$ & \\
\hline Site & & & 0.459 & & 0.128 & & 0.030 \\
\hline Colon & 17 & $1.020 \pm 0.873$ & & $-0.469 \pm 0.857$ & & $-0.780 \pm 0.726$ & \\
\hline Rectum & 81 & $1.209 \pm 0.969$ & & $-0.115 \pm 0.868$ & & $-0.297 \pm 0.841$ & \\
\hline TNM staging & & & 0.026 & & 0.602 & & 0.982 \\
\hline $\mathrm{I}+\mathrm{II}$ & 45 & $0.945 \pm 1.029$ & & $-0.226 \pm 0.946$ & & $-0.379 \pm 0.881$ & \\
\hline III + IV & 53 & $1.372 \pm 0.841$ & & $-0.133 \pm 0.811$ & & $-0.383 \pm 0.810$ & \\
\hline Local invasion & & & 0.024 & & 0.112 & & 0.321 \\
\hline $\mathrm{T}_{1}+\mathrm{T}_{2}+\mathrm{T}_{3}$ & 62 & $1.012 \pm 0.981$ & & $-0.283 \pm 0.901$ & & $-0.445 \pm 0.871$ & \\
\hline $\mathrm{T}_{4}$ & 36 & $1.459 \pm 0.837$ & & $0.008 \pm 0.800$ & & $-0.270 \pm 0.781$ & \\
\hline Vessel invasion & & & 0.887 & & 0.819 & & 0.647 \\
\hline Yes & 12 & $1.213 \pm 0.668$ & & $-0.122 \pm 0.808$ & & $-0.276 \pm 0.653$ & \\
\hline No & 86 & $1.171 \pm 0.987$ & & $-0.184 \pm 0.885$ & & $-0.396 \pm 0.864$ & \\
\hline Differentiation & & & 0.515 & & 0.913 & & 0.886 \\
\hline Better & 69 & $1.135 \pm 0.922$ & & $-0.170 \pm 0.883$ & & $-0.373 \pm 0.845$ & \\
\hline Worse & 29 & $1.273 \pm 1.028$ & & $-0.191 \pm 0.860$ & & $-0.400 \pm 0.840$ & \\
\hline CEA (ng/ml) & & & 0.487 & & 0.550 & & 0.394 \\
\hline$\leqslant 3.4$ & 13 & $1.065 \pm 1.365$ & & $-0.213 \pm 1.040$ & & $-0.500 \pm 0.827$ & \\
\hline$>3.4$ & 14 & $1.350 \pm 0.637$ & & $-0.014 \pm 0.632$ & & $-0.271 \pm 0.522$ & \\
\hline
\end{tabular}

$\mathrm{SD}$, standard deviation; CEA, carcinoembryonic antigen.

el $(p>0.05)$. MiR-143 expression had no relationship with the clinicopathological features investigated $(p>$ 0.05 , Table 3).

As the miR-143 and miR-145 expression were related to cancer site, we further analyzed the relationship between miR-145 and clinicopathological features in colon or rectal cancer. There was no any significant relationship ( $p>0.05$, data not shown).

We also examined the relationship of the combined expression of the three miRNAs with clinicopathological features, namely, the cases with up-regulated miR-31 and both down-regulated miR-143 and miR-
145 (pattern1), the cases with up-regulated miR-31 and down-regulated miR-143 (pattern 2) or with downregulated miR-145 (pattern 3), and the cases with both down-regulated miR-143 and miR-145 (pattern 4). None of the expressed patterns had a relationship with the clinicopathological features $(p>0.05$, data not shown).

\section{Discussion}

Current knowledge of molecular alterations that are 


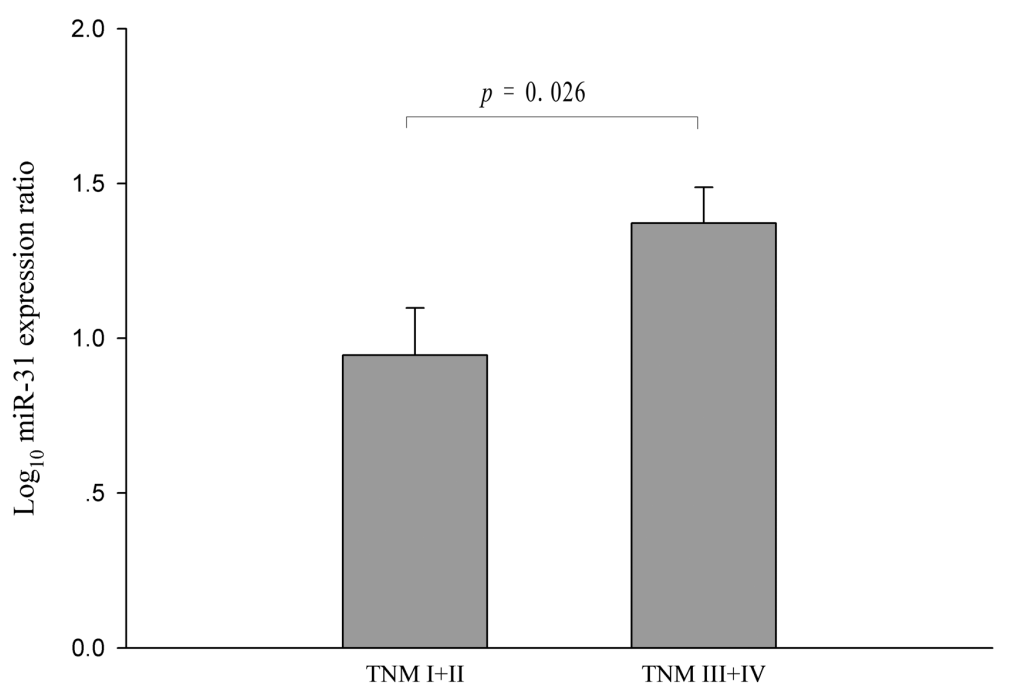

Fig. 1. Correlation between miR-31 expression and TNM stage in patients with colorectal cancer. Difference was significant between TNM stage I + II and stage III + IV $(p=0.026)$.

important for CRC include epigenetic and genetic changes in key tumor suppressors and oncogenes is extensive, however, it still represents the tip of the iceberg of knowledge that needs to be resolved for a complete understanding of the CRC pathogenesis, especially the nature history [27]. The recently identified class of non-protein-coding small RNAs, miRNAs, may provide a new insight in cancer research [28]. The body of expression data for miRNAs in cancer available to date suggests that miRNAs may have a diagnostic potential. However, initial expression studies focused on comparing normal tissues to tumors, to gauge diagnostic potential it will be more important to correlate miRNA expression with tumor subtypes or clinical parameters [29].

In the present study, we analyzed 98 samples of CRCs and the corresponding normal mucosa, including 17 cases of colon cancer and 81 of rectal cancer, to identify the expression of miR-31, -143 and -145 . MiR-31 was up-regulated in the majority of the CRCs (91\% of 98), which is in line with the previous two studies, one included 12 pairs of CRCs and non-tumoral mucosa samples [17], and the other included 29 primary colon cancers and 6 non-tumor adjacent tissue [18]. We also found that miR-145 was down-regulated in either colon or rectal cancer, while miR-143 was downregulated in colon cancer, but not in rectal cancer. To our knowledge, this is the first study to elucidate the difference of miR-143 expression between colon and rectal cancer. Although previous four studies showed that the miR-143 and miR-145 were down-regulated in CRC $[7,18,22,30]$, there were only 6 rectal cancers in the first three studies, and the last one included only 4 CRCs, the location of which was not elucidated. Taken together, these observations imply that the miR-31, miR-143 and miR-145 may play a certain role in the development of colon and/or rectal cancer.

In our study, the miR-31 expression was not only related to TNM stage but also related to tumor invasion. The level of miR-31 expression at TNM stage III and IV was higher than that at stage I and II (Fig. 1). Bandrés et al. previously also examined miR-31 expression in relation to tumor stage, but they only included 5 CRCs for each stage II and IV, where tumors with stage IV had a significantly up-regulated miR-31 expression than those with stage II [17]. More recently, Slaby et al. found no association between miR-31 expression and TNM stage [18]. This discrepancy may partly due to the specimens analyzed. The specimens studied by Slaby et al. were all colon cancer ( 29 cases), and with 6 non-tumor adjacent mucosa as comparison. In our study, the specimens included not only colon cancer (17 cases) but also rectal cancer (81 cases). Furthermore, we found that the tumors which invaded adjacent tissues or organs had more miR-31 expression than those limited to the wall of the colon and rectum. The downexpression of miR-145 in colon cancer was lower than that in the rectal cancer, and there was no relationship of miR-143 and miR-145 expression with other clinicopathological variables. Thus, the miR-31 may be an important oncomiR, which can cleavage or inhibit the targeted mRNAs of tumor suppressor gene(s), and play a role in the progression of CRC. While the miR- 
143 and miR-145 were not significantly involved in the progression of the disease.

The lack of knowledge about the targets for miR31 hampered a full understanding on the biological functions deregulated by miR-31 aberrant expression. We used miRGen to predict gene targets [31], and it may be expected that the target of miR-31 belong to the class of tumor suppressor genes or genes encoding proteins with potential tumor suppressor functions. BAP1, a tumor suppressor gene that functions in the BRCA1 growth control pathway [32]; HIF1AN, inhibits HIF1A transcriptional activity [33]; MAPK transduction protein such as MAP4K5; RAS homologues RAB14, RAB6B, and RASA1 were found as potential targets of miR-31. Interestingly, DICER1, the RNA processing enzyme to produce the mature miRNAs [34], was one of the potential targets too, suggesting that miR-31 may regulate the expression of other miRNAs. Clearly, further studies are required to determine the interactions of miR-31 with their potential targets. MiR-143 negatively regulates ERK5 mRNA at translational level [21]. Both insulin receptor substrate1 (IRS-1) and type I insulin-like growth factor receptor (IGF-IR) were experimentally verified the targets of miR-145 in colon cancer lines, and the cells transfected with miR-145 had a tendency to accumulate in the G2 phase of cell cycle [35]. Therefore, persistent decreased levels of miR-143 and miR-145 might target the ERK5 or ISR-1, IGF-IR, respectively, and may be directly involved in tumorigenesis of CRC.

In conclusion, miR-31 was up-regulated in CRC, especially in cancers with advanced TNM stage and deeper invasion. MiR-145 was down-regulated both in the colon cancer and rectal cancer, while miR-143 was only down-regulated in the colon cancer. The miR-143 and miR-145 downexpression had no relationship with other clinicopathological features, except that the miR145 expression was related to cancer site. The results indicate that miR-31 expression may be important in the development and progression of CRC. While the miR-143 and miR-145 may play a certain role in the development of colon and/or rectal cancers but not in progression of the disease.

\section{Acknowledgements}

This work was supported by the grant from the China Medical Board (CMB, 96636). We thank Jun-Li Ding, Jian-Ting Guan and Fang $\mathrm{Xu}$ for their technical assistance.

\section{References}

[1] D.P. Bartel, MicroRNAs: genomics, biogenesis, mechanism, and function, Cell 116 (2004), 281-297.

[2] B.J. Reinhart, F.J. Slack, M. Basson, A.E. Pasquinelli, J.C. Bettinger, A.E. Rougvie, H.R. Horvitz and G. Ruvkun, The 21-nucleotide let-7 RNA regulates developmental timing in Caenorhabditis elegans, Nature 403 (2000), 901-906.

[3] A.M. Cheng, M.W. Byrom, J. Shelton and L.P. Ford, Antisense inhibition of human miRNAs and indications for an involvement of miRNA in cell growth and apoptosis, Nucleic Acids Res 33 (2005), 1290-1297.

[4] C.Z. Chen, L. Li, H.F. Lodish and D.P. Bartel, MicroRNAs modulate hematopoietic lineage differentiation, Science $\mathbf{3 0 3}$ (2004), 83-86.

[5] A. Cimmino, G.A. Calin, M. Fabbri, M.V. Iorio, M. Ferracin, M. Shimizu, S.E. Wojcik, R.I. Aqeilan, S. Zupo, M. Dono, L. Rassenti, H. Alder, S. Volinia, C.G. Liu, T.J. Kipps, M. Negrini and C.M. Croce, miR-15 and miR-16 induce apoptosis by targeting BCL2, Proc Natl Acad Sci USA 102 (2005), 1394413949.

[6] G.A. Calin, C.D. Dumitru, M. Shimizu, R. Bichi, S. Zupo, E. Noch, H. Aldler, S. Rattan, M. Keating, K. Rai, L. Rassenti, T. Kipps, M. Negrini, F. Bullrich and C.M. Croce, Frequent deletions and down-regulation of micro- RNA genes miR15 and miR16 at 13q14 in chronic lymphocytic leukemia, Proc Natl Acad Sci USA 99 (2002), 15524-15529.

[7] M.Z. Michael, S.M. O' Connor, N.G. van Holst Pellekaan, G.P. Young and R.J. James, Reduced accumulation of specific microRNAs in colorectal neoplasia, Molecular Cancer Research 1 (2003), 882-891.

[8] J. Takamizawa, H. Konishi, K. Yanagisawa, S. Tomida, H. Osada, H. Endoh, T. Harano, Y. Yatabe, M. Nagino, Y. Nimura, T. Mitsudomi and T. Takahashi, Reduced expression of the let-7 microRNAs in human lung cancers in association with shortened postoperative survival, Cancer Res 64 (2004), 3753-3756.

[9] M.V. Iorio, M. Ferracin, C.G. Liu, A. Veronese, R. Spizzo, S. Sabbioni, E. Magri, M. Pedriali, M. Fabbri, M. Campiglio, S. Ménard, J.P. Palazzo, A. Rosenberg, P. Musiani, S. Volinia, I. Nenci, G.A. Calin, P. Querzoli, M. Negrini and C.M. Croce, MicroRNA gene expression deregulation in human breast cancer, Cancer Res 65 (2005), 7065-7070.

[10] E.J. Lee, Y. Gusev, J. Jiang, G.J. Nuovo, M.R. Lerner, W.L. Frankel, D.L. Morgan, R.G. Postier, D.J. Brackett and T.D. Schmittgen, Expression profiling identifies microRNA signature in pancreatic cancer, Int J Cancer 120 (2007), 1046-1054.

[11] W.O. Lui, N. Pourmand, B.K. Patterson and A. Fire, Patterns of known and novel small RNAs in human cervical cancer, Cancer Res 67 (2007), 6031-6043.

[12] M.V. Iorio, R. Visone, G. Di Leva, V. Donati, F. Petrocca, P. Casalini, C. Taccioli, S. Volinia, C.G. Liu, H. Alder, G.A. Calin, S. Ménard, J.P. Palazzo, A. Rosenberg, P. Musiani, S. Volinia, I. Nenci, G.A. Calin, P. Querzoli, M. Negrini and C.M. Croce, MicroRNA signatures in human ovarian cancer, Cancer Res 67 (2007), 8699-8707.

[13] M. Ozen, C.J. Creighton, M. Ozdemir and M. Ittmann, Widespread deregulation of microRNA expression in human prostate cancer, Oncogene 27 (2008), 1788-1793.

[14] A. Esquela-Kerscher and F.J. Slack, Oncomirs - microRNAs with a role in cancer, Nat Rev Cancer 6 (2006), 259-269.

[15] A.J. Schetter, S.Y. Leung, J.J. Sohn, K.A. Zanetti, E.D. Bowman, N. Yanaihara, S.T. Yuen, T.L. Chan, D.L. Kwong, G.K. $\mathrm{Au}$, C.G. Liu, G.A. Calin, C.M. Croce and C.C. Harris, Mi- 
croRNA expression profiles associated with prognosis and therapeutic outcome in colon adenocarcinoma, JAMA 299 (2008), 425-436.

[16] M. Lagos-Quintana, R. Rauhut, W. Lendeckel and T. Tuschl, Identification of novel genes coding for small expressed RNAs, Science 294 (2001), 853-858.

[17] E. Bandrés, E. Cubedo, X. Agirre, R. Malumbres, R. Zárate, N. Ramirez, A. Abajo, A. Navarro, I. Moreno, M. Monzó and J. García-Foncillas, Identification by real-time PCR of 13 mature microRNAs differentially expressed in colorectal cancer and non-tumoral tissues, Mol Cancer 19 (2006), 5-29.

[18] O. Slaby, M. Svoboda, P. Fabian, T. Smerdova, D. Knoflickova, M. Bednarikova, R. Nenutil and R. Vyzula, Altered expression of miR-21, miR-31, miR-143 and miR-145 is related to clinicopathologic features of colorectal cancer, Oncology 72 (2007), 397-402.

[19] M. Lagos-Quintana, R. Rauhut, A. Yalcin, J. Meyer, W. Lendeckel and T. Tuschl, Identification of tissue-specific microRNAs from mouse, Curr Biol 12 (2002), 735-739.

[20] Y. Akao, Y. Nakagawa, Y. Kitade, T. Kinoshita and T. Naoe, Downregulation of microRNAs-143 and -145 in B-cell malignancies, Cancer Sci 98 (2007), 1914-1920.

[21] Y. Akao, Y. Nakagawa and T. Naoe, MicroRNAs 143 and 145 are possible common onco-microRNAs in human cancers, Oncol Rep 16 (2006), 845-850.

[22] W.C. Cho, OncomiRs: the discovery and progress of microRNAs in cancers, Mol Cancer 6 (2007), 60.

[23] C. Chen, D.A. Ridzon, A.J. Broomer, Z. Zhou, D.H. Lee, J.T. Nguyen, M. Barbisin, N.L. Xu, V.R. Mahuvakar, M.R. Andersen, K.Q. Lao, K.J. Livak and K.J. Guegler, Real-time quantification of microRNAs by stem-loop RT-PCR, Nucleic Acids Res 33 (2005), e179.

[24] S.R. Hamilton and L.A. Aaltonen, editors, Pathology and Genetics of Tumours of the Digestive System, Lyon: IARC Press, 2000, 104.

[25] M.W. Pfaffl, G.W. Horgan and L. Dempfle, Relative expression software tool (REST) for group-wise comparison and statistical analysis of relative expression results in real-time PCR, Nucleic Acids Res 30 (2002), e36.

[26] T. Mygind, S. Birkelund, N.H. Birkebaek, L. Østergaard, J.S. Jensen and G. Christiansen, Determination of PCR efficiency in chelex-100 purified clinical samples and comparison of real-time quantitative PCR and conventional PCR for detection of Chlamydia pneumoniae, BMC Microbiol 2 (2002), 17.

[27] A. Umar and S. Srivastava, The promise of biomarkers in colorectal cancer detection, Dis Markers 20 (2004), 87-96.

[28] B. Zhang, X. Pan, G.P. Cobb and T.A. Anderson, microRNAs as oncogenes and tumor suppressors, Dev Biol 302 (2007), $1-12$.

[29] C. Blenkiron and E.A. Miska, miRNAs in cancer: approaches, aetiology, diagnostics and therapy, Hum Mol Genet 16 (2007), R106-R113.

[30] J.M. Cummins, Y. He, R.J. Leary, R. Pagliarini, LA. Jr. Diaz, T. Sjoblom, O. Barad, Z. Bentwich, A.E. Szafranska, E. Labourier, C.K. Raymond, B.S. Roberts, H. Juhl, K.W. Kinzler, B. Vogelstein and V.E. Velculescu, The colorectal microRNAome, Proc Natl Acad Sci USA 103 (2006), 3687-3692.

[31] M. Megraw, P. Sethupathy, B. Corda and A.G. Hatzigeorgiou, miRGen: a database for the study of animal microRNA genomic organization and function, Nucleic Acids Res 35 (2007), 149-155.

[32] D.E. Jensen, M. Proctor, S.T. Marquis, H.P. Gardner, S.I. Ha, L.A. Chodosh, A.M. Ishov, N. Tommerup, H. Vissing, Y. Sekido, J. Minna, A. Borodovsky, D.C. Schultz, K.D. Wilkinson, G.G. Maul, N. Barlev, S.L. Berger, G.C. Prendergast and F.J. 3rd. Rauscher, BAP1: a novel ubiquitin hydrolase which binds to the BRCA1 RING finger and enhances BRCA1-mediated cell growth suppression, Oncogene 16 (1998), 1097-1112.

[33] P.C. Mahon, K. Hirota and G.L. Semenza, FIH-1: a novel protein that interacts with HIF-1alpha and VHL to mediate repression of HIF-1 transcriptional activity, Genes Dev 15 (2001), 2675-2686.

[34] S. Chiosea, E. Jelezcova, U. Chandran, J. Luo, G. Mantha, R.W. Sobol and S. Dacic, Overexpression of Dicer in precursor lesions of lung adenocarcinoma, Cancer Res 67 (2007), 23452350.

[35] B. Shi, L. Sepp-Lorenzino, M. Prisco, P. Linsley, T. deAngelis and R. Baserga, Micro RNA 145 targets the insulin receptor substrate-1 and inhibits the growth of colon cancer cells, $J$ Biol Chem 282 (2007), 32582-32590. 


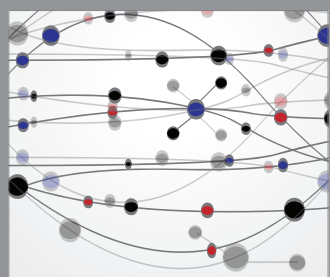

The Scientific World Journal
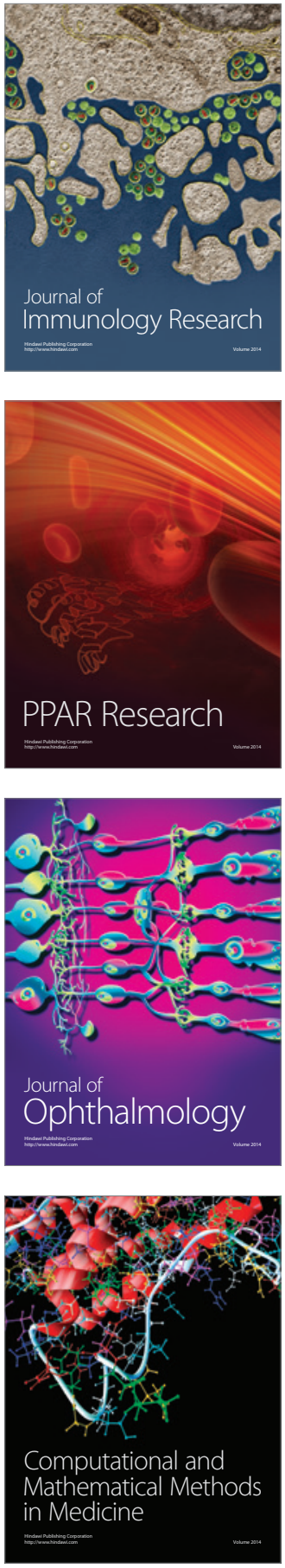

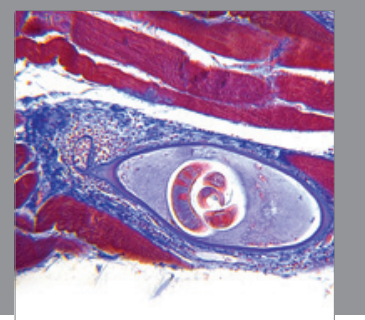

Gastroenterology

Research and Practice
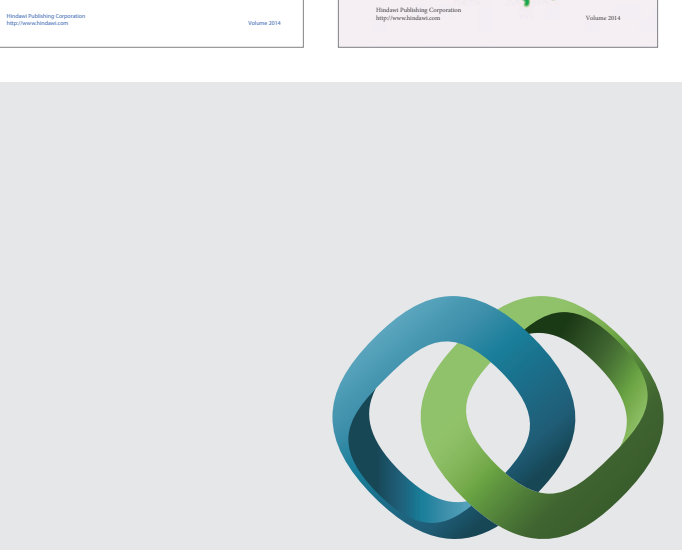

\section{Hindawi}

Submit your manuscripts at

http://www.hindawi.com
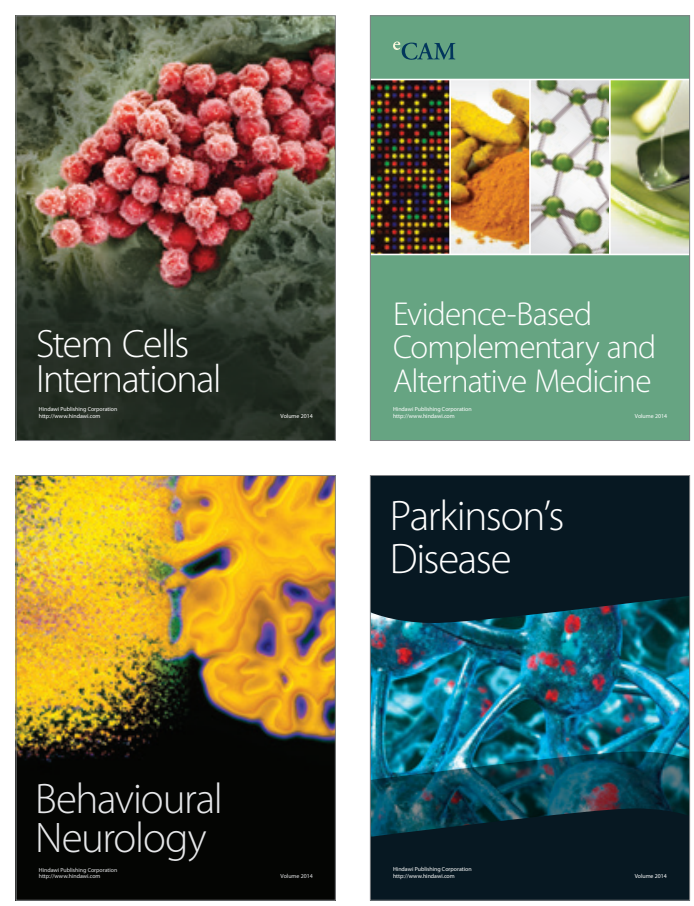

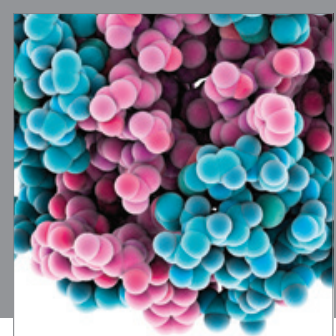

Journal of
Diabetes Research

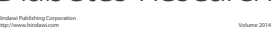

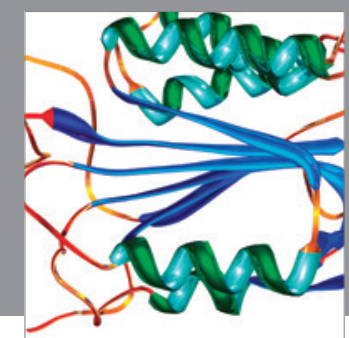

Disease Markers
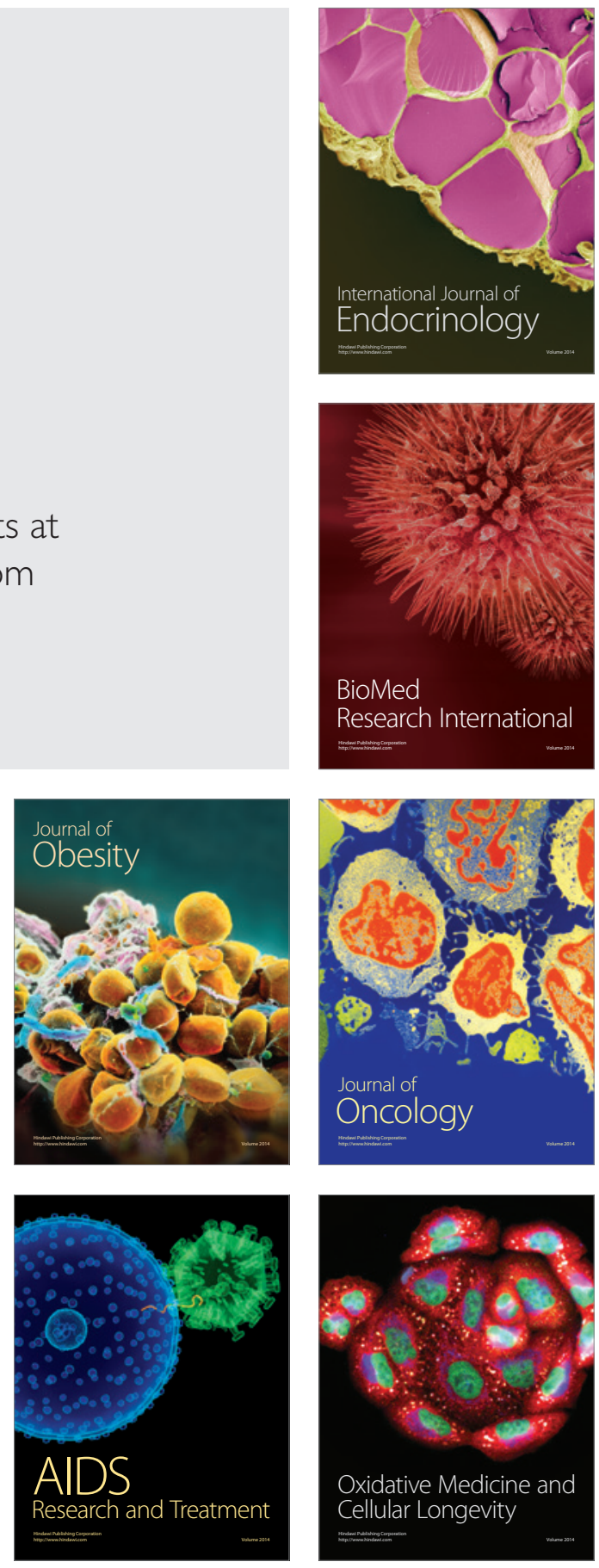